\title{
Effectiveness of The Back School and The Pilates Method in Disability and Pain of Patients With Chronic Non-Specific Low Back Pain. Randomized Controlled Clinical Trial.
}

Mario Manuel López Mesa ( $\square$ mariomlopezm@gmail.com )

Universidad Alfonso X el Sabio Facultad de Ciencias de la Salud https://orcid.org/0000-0002-0452-

1570

Javier Julian Cabrerizo Fernandez

Hospital Universitario del Henares

Antonio Lopez Roman

Universidad Alfonso X El Sabio

Eva Maria Rodriguez Fernandez

Universidad Alfonso X El Sabio

\section{Research}

Keywords: School of the Back, Pilates, low back pain, therapeutic exercise, disability.

Posted Date: September 28th, 2020

DOI: https://doi.org/10.21203/rs.3.rs-27957/v1

License: (c) (1) This work is licensed under a Creative Commons Attribution 4.0 International License.

Read Full License 
Effectiveness of the Back School and the Pilates Method in disability and pain of patients with chronic non-specific low back pain. Randomized controlled clinical trial.

López-Mesa MM(1) (2), Cabrerizo-Fernández JJ(1), López-Román A(3), RodríguezFernández EM(4)

(1) Rehabilitation and Physiotherapy Service of the Hospital Universitario del Henares. Avenida de España, s/n. Coslada. Comunidad de Madrid. Spain.

(2) Dr. Mario Manuel López Mesa, Doctor in Physiotherapy. Department of Physiotherapy. Department of Physiotherapy of University of Alfonso X "Ël Sabio", Villanueva de la Cañada. Community of Madrid, Spain. (UAX)

(3) Dr. Antonio López-Román. Doctor of Medicine, Department of Medicine of University of Alfonso X "Ël Sabio", Villanueva de la Cañada. Community of Madrid, Spain. (UAX)

(4) Dra. Eva M. Rodríguez Fernández, Doctor in Physiotherapy. Department of Physiotherapy of University of Alfonso X "Ël Sabio", Villanueva de la Cañada. Community of Madrid, Spain. (UAX)

Principal investigator's address:

Dr. Mario Manuel López Mesa

mariomlopezm@gmail.com teléfono 691613598

Av. de Francia buzón 482 Torre A1 piso 6B, Los Ángeles de San Rafael (Segovia). CP 40424. Spain. 
Effectiveness of the Back School and the Pilates Method in disability and pain of patients with chronic non-specific low back pain. Randomized controlled clinical trial.

Keywords: School of the Back, Pilates, low back pain, therapeutic exercise, disability.

\section{$\underline{\text { Abstract }}$}

Objective: The purpose was to compare the effectiveness of the Pilates Method versus the Back School in specialized care, assessing improving the disability with the Roland Morris questionnaire and the perceived pain with the visual analog scale (VAS) in people with non-specific chronic low back pain.

Method: Single-blind randomized controlled trial to determine the effects of the Pilates Method for patients with low back pain compared to Back School exercises, two groups of 48 patients, 3-month treatment period.

Results: The Pilates Group (GP) recorded significant improvements in all of the variables that were the subject for this research, compared to those provided by the Back School Group (GEE).

In the Roland Morris questionnaire of 0,41 points [GP (Mean difference [MD] Pretreatment-posttreatment $=2,08 ; 95 \%$ confidence interval $[\mathrm{CI}]=1,21$ to 2,$95 ; \mathrm{p}=0,001$ ) vs $\operatorname{GEE}(\mathrm{MD}=1,66 ; 95 \%$ confidence interval $[\mathrm{CI}]=0,90$ to 2,$43 ; \mathrm{p}=0,001)]$.

In the visual analog scale (VAS) of 0,40 points [GP (Mean difference [MD] Pretreatmentposttreatment $=1,82 ; 95 \%$ confidence interval $[\mathrm{CI}]=1,24$ to 2,$40 ; \mathrm{p}=0,001$ ) vs GEE $(\mathrm{MD}=1,42 ; 95 \%$ confidence interval $[\mathrm{CI}]=0,82$ to 2,$04 ; \mathrm{p}=0,001)]$.

Conclusions: The treatment of nonspecific low back pain with therapeutic Pilates is more effective than the therapeutic treatment of the Back School, both in terms of functional disability and intensity of pain.

Trial registration: This trial is registered in http://www.ensaiosclinicos.gov.br/rg/RBR5nk2tr/, with the ID number of RBR-5nk2tr , date of trial registration 4/11/2019. 


\section{Background}

This research study is part of the investigative work of the Hospital del Henares and in the commitment to offer its patients more specific physiotherapeutic treatments, by means of scientific verification of the Pilates practice, it can be used to reduce pain and improve functionality. Advances in research in low back pain (LBP) rehabilitation treatments acquire great importance due to the negative impact that this pathology has on Spanish society. The Spanish Society of Rheumatology carried out in 2002 the EPISER study with the aim of estimating the impact of musculoskeletal diseases on the Spanish adult population, reflecting that low back pain has a significant impact on the performance of people's normal activities who suffer from it and their quality of life, whose impact extrapolated to the general population means that more than two million people, in the six-month interval, stop carrying out their usual main activity for at least one day, of which more than One million people are in a situation of incapacity for work in that sixmonth period [1].

The therapeutic effects that exercise has to prevent low back pain can be several: reinforcement of the back muscles, increased flexibility of the trunk, increased regional blood supply to the muscles, joints and discs to reduce possible local injuries and promote tissue repair; and improvement of the state of mind, thus altering the perception of pain [2]. For the above reasons, lack of activity for an excessive time is detrimental for different reasons: mental sensation of serious illness, loss of muscle mass and flexibility, loss of bone mass, decreased disc nutrition, cardiovascular deconditioning syndrome and economic losses. [3]

The purpose of this research is to ensure that the determination of the effectiveness of the Pilates Method exercise for LBP is based on scientific evidence so as not to waste staff time and resources and avoid unnecessary stress for LBP patients. Therefore, we conducted a single-blind randomized controlled trial to determine the effects of the Pilates Method for patients with low back pain compared to Back School exercises.

\section{Objective:}

Compare the effectiveness of the Pilates Method versus the Back School in terms of improving disability and reducing pain intensity.

Secondary objectives

$\checkmark$ Analyze and compare the efficacy of both treatments regarding the level of functional disability using the Roland Morris Questionnaire.

$\checkmark$ Analyze and compare the efficacy of both treatments with respect to the level of pain intensity by analyzing and evaluating the improvement obtained from the EVA score.

$\checkmark$ Determine the size of the effects of the treatments using Cohen's $d$ and Glass's $\Delta$.

$\checkmark$ Determine if the effects of the treatments suppose clinically relevant minimal changes in the health of the patients. 


\section{Methods and Design}

A longitudinal pretest-posttest study of a sample is designed making an assessment at the beginning of the intervention and another right after the Pilates and back school program.

Controlled, double-blind, comparative clinical trial of two groups (Pilates and School of the Back group)

\section{$\underline{\text { Research question: }}$}

Do patients with non-specific low back pain, treated with technics using therapeutic Pilates exercises, compared to those treated with School of the Back exercises obtain better results in pain intensity and functional disability?

\section{Hypothesis.}

Therapeutic Pilates treatment in patients with non-specific low pain, compared to conventional treatment of the School of the Back, has a greater effectiveness in the treatment of pain and improvement of functional disability.

\section{Individuals.}

A patient's recruitment was carried out during the las months of 2015 on waiting list of the Hospital del Henares with a foresight of the start of rehabilitation treatments in early 2016. A previous review of the patient's medical records, the number of patients diagnosed with chronic non-specific low back pain that met the inclusion criterion and without criteria of this investigation were 53

\section{Sampling}

- Two groups of patients with non-specific low back pain:

A) Comparison group (application of Therapeutic Pilates exercises)

B) Comparison group (application of exercises from the School of the Back)

\section{SAMPLE. -}

- Representative patients, 18 years of age and over with non-specific low back pain.

\section{Inclusion criterio for the two techniques:}

1.- 18 years old and over

2.- In rehabilitación preccess treatment or on Hospital waiting list.

3.- Affected patients with non-specific low back pain with more tan a three month evolution. 
4.-Patientes without carrying out any other pyhsiotherapeutic treatment.

\section{Exclusion criteria for the two techniques:}

Lack of collaboration, incorrect diagnoses, incorrect treatment assignment, forbiden use of concomitant medication (s) and insufficient adherence to treatment.

1.- Under 18 years of age and over 80 years (difficulty and risk in carrying out the treatments)

2.- Nonhospital patients.

3.-Less than three months of the pathology's evolution.

4.-Pathology with specific nerve roots diagnosis.

5.-Patients who have gone through a surgical process directly directed to low back pain.

6.- Presence of other associated systemic or musculotendinous pathologies.

7.- Patients who are in process of receiving physiotherapeutic treatment that may alter results.

8.- Patients with kidney, liver, lung, adrenal and heart failure.

9.- Acute infectious disease while they last. -

10.- Chronic infectious disease.

11.- Metabolic diseases (diabetes, high blood pressure, anorexia) not under control.

12.- Non treated hypertension

13.- Inflammation of the musculoskeletal system (myositis, arthritis) in its acute phase.

14.- Diseases that cause asthenia or muscle fatigue.

15.- Diseases that disturb the balance or cause vertigo.

16.- Pregnant women. Can do moderate exercise with very low impact.

17.- People with pre-existing heart illness.

18. People with pre-existing or chronic musculoskeletal injuries or disorders according to the doctor's evaluation.

\section{Recruitment procedure and sample calculation:}

The number of patients in the rehabilitation treatment process or on a hospital waiting list with foresight planning to start their rehabilitation treatments in February, corresponding to all pathologies, as of January $31^{\text {st }}$, 2016, was $102(n=102)$. 
After reviewing the medical records of the 102 patients, the number or patients affected and diagnosed with non-specific low back pain with more than 3 months of evolution, as of January 31 st were 54.

Of these 54 patients, one was excluded due to him being underage, therefore the total of patients that met al.1 the inclusion criteria was a total of $53(54-1=53)$.

Of these 53 patients, 5 did not complete the treatment therefore they were assisted by rehabilitation medical treatments other than the School of the B ack, or Pilates (figure 1)

The participants were not informed, at any time, as to whether the type of exercises they were going to perform corresponded to the Pilates Group or the School of the Back Group, not knowing, at any time, which group they had been assigned to. The treatments of both groups were carried out at different times, patients belonging to different treatment groups did not have contact with each other.

The sample $(\mathrm{n}=53)$ was divided into two groups by means of the computer program "IBM.SPSS. Statistics.v20. Multilingual". This program, using a randomization procedure, divided the participating individuals into two groups (A and B), A was assigned as the Pilates Method treatment group $(n=27)$ and B was assigned as a treatment group of the School of the Back $(n=26)$.

Sample calculation:

A) Regarding the size of the population of the study, actual updated data must be collected, so for this study, the data collected in the 2015 Report of the "Hospital Universitario del Henares" published in the edition 5/2016 on the structure of the population assigned to the scope of the Hospital de Henares.

B) To estimate the proportion of patients who may suffer from chronic low-back pain in a year's time in Spain, the results of the EPISER study indication $[1,3,4]$ were considered.

The estimated prevalence of low back pain in the Spanish adult population (over 20 years of age $)$ is $14.8 \%(95 \%$ confidence interval $[\mathrm{CI}]=12.2-17.4)$; During a 6month period, the probability of suffering at least one episode of low back pain in Spain is $44.8 \%$ (95\% confidence interval $[\mathrm{CI}]=39.9-49.8)$; the estimated prevalence of people with chronic low back pain among Spanish adults is $7.7 \%$ (95\% confidence interval $[\mathrm{CI}]=4.7-11.6)$, and the estimated prevalence of people with low back pain of inflammatory characteristics is $0.8 \%(95 \%$ confidence interval $[\mathrm{CI}]=0.6-1.0)$.

Therefore, as it is a research study in patients with chronic low back pain, $7.7 \%$ is taken as the reference proportion, which indicates the proportion of individuals affected by chronic low back pain.

With a confidence level of $95 \%$, and a prevalence of $7.7 \%$, the resulting sample size is that of 53 patients. 
The sample calculated in this study occurs with those obtained using the Excell calculator provided by the Clinical Epidemiology and Biostatistics Unit of the Complexo Hospitalario Universitario a Coruña [5]

Due to the above mentioned data, the sample of our study will consist of a minimum of 53 patients, therefore, 2 groups of 24 to 27 patients each of which one will get the treatment from the School of the Back and the other will have the Pilates Method with a high index of confidence compatible with the human, material and time resources available at the Physiotherapy Unit of the Hospital del Henares

To carry out the treatments, a great effort and collaboration will be required from all the staff of the Physiotherapy Unit of the Hospital del Henares who will provide their services and collaboration to carry out this research without harming the usual care of patients who have to go through the rehabilitation of other pathologies. 


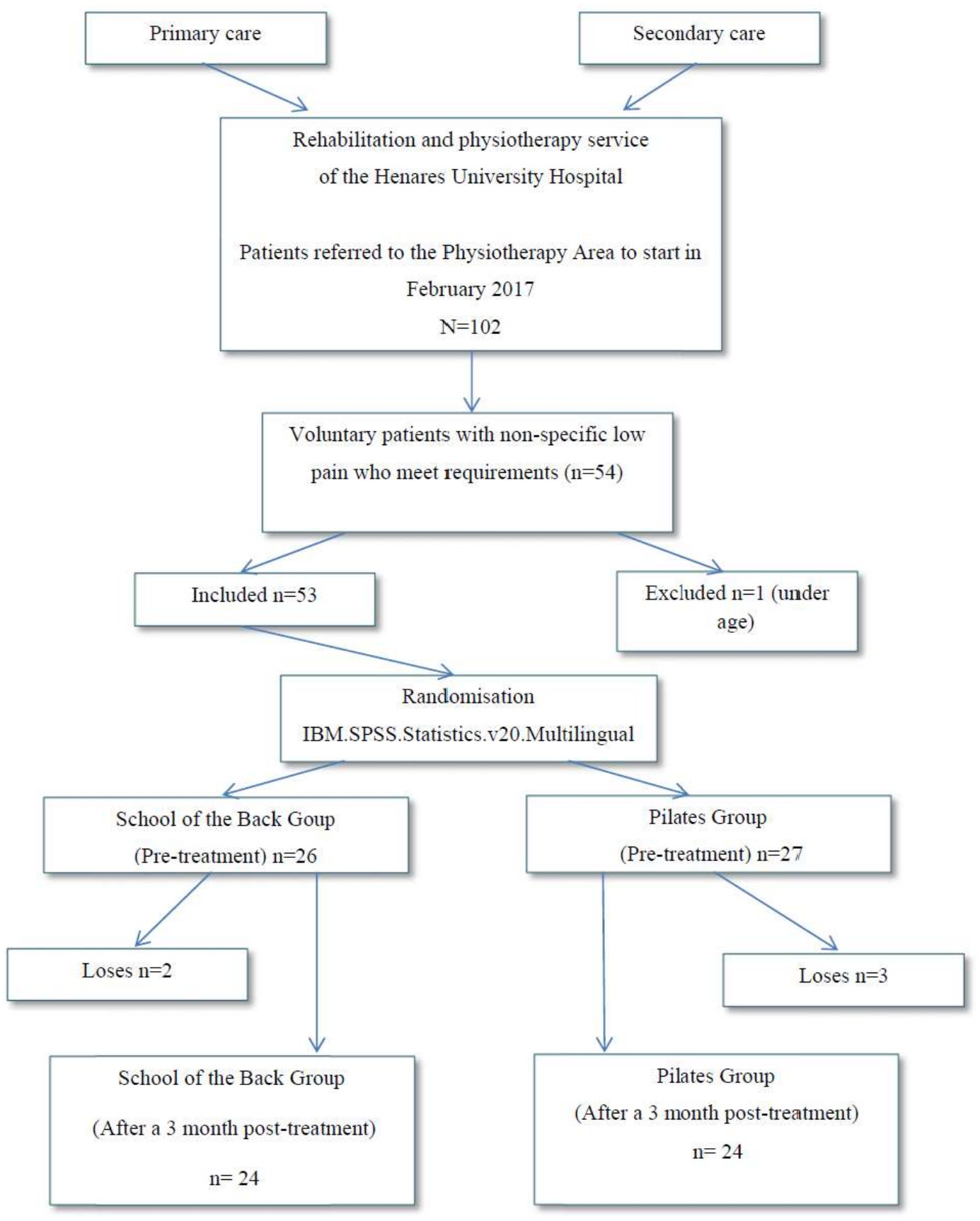

Figure 1.- Study Design. Recruitment, randomization to treatment, and voluntary recruitment of participants. 


\section{Interventions:}

The sessions are distributed over two days a week and consists of individual manual treatment by the physical therapist and the performance of a group program with a maximum of five to eight patients. In the part corresponding to manual individual treatment, an individualized assessment of the needs of each patient is carried out and in the group session, an exercise program of the School of the Back or the Pilates Method is carried out (depending on the Group to which each patient is assigned) supervised by a physical therapist who individually corrects each patient. The sessions last between 60 to 90 minutes each, dedicating 20 minutes to manual therapy and 40 to the group session approximately. The total duration of treatment was 12 weeks.

The exercises performed in the treatment sessions were:

In the Group of the School of the Back following the recommendations made by the Spanish Society of Rehabilitation and Medicine on its website [6].

Stretching exercises for the back, lumbar pelvic area and back of the lower limbs (lumbosacral stretch, cat, hamstring, lumbosacral and psoas stretches, cat exercise), Vertebral flexion exercises, strengthening exercises of the abdominal musculature (upper and lower abdominals in front, extended leg elevation and crossed upper abdominals), strengthening exercises for the paravertebral musculature, back extension (supine flexions, trochus extensions prone), gluteal musculature strengthening exercises (simultaneous quadruped arm and leg lifts, extended lateral leg and bridge lift) and standing and supine pelvic scale exercises.

In the Pilates Group following the exercises and recommendations of Isacowitz, and Clippinger [7] in his book entitled Anatomy of Pilates.

Single leg lift, leg circles, roll up, hundred, side kick, twist, single leg stretch, spine stretch, swimming, double leg stretch

\section{Measurements}

A follow up and control was done prior to the start of treatments and another control after three months (12 weeks) of rehabilitation carried out at the Henares University Hospital

- Evaluation of functional status disability using the Roland-Morris Questionnaire.

- Evaluation of pain using Visual Analog Pain Scale (VAS)

- The size of the effects of treatment is analyzed and calculated using Cohen's d and Glass's A

\section{$\underline{\text { Adverse events }}$}

Participants will be asked about adverse experiences in each treatment session. We will define an adverse experience as any unintentional unfavorable sign, symptom, or disease temporarily associated with the therapeutic use of Pilates or Back School exercises that 
could reasonably be related to the interventions. If a participant develops a serious adverse experience (i.e. any adverse event that occurs during treatment which results in any of the following results: death, a threat to life adverse event, hospitalization or prolongation of existing, persistent or disability / significant disability), will be immediately informed to the Physiotherapy Service of the Hospital del Henares.

\section{$\underline{\text { Statistical analysis }}$}

Using IBM SPSS Statistics versus 20 Multilingual. The effects of the two therapies in relation to the level of disability are estimated using the Roland Morris Questionnaire and pain scores using the visual analog scale (VAS) score (descriptive and inferential statistics) and at the same time the size of treatment using Cohen's d and Galss' A.

- The calculation of Cohen's d, using the proposed formula by its creator Jacob Cohen, to be able to calculate how different the groups are. According to the author's conclusions, the results show the size of the clinical effect $(>0.20$ and $<0.50$ small clinical effect size $>0.50$ and $<0.80$ moderate clinical effect size and $>$ 0.80 size of the large clinical effect [8]. Cohen's $d$ is one of the most widely used measures in specialized publications to calculate the effect size of treatments and in meta-analytic studies $[9,10]$.

Cohen's $d$ is determined by calculating the mean difference between your two groups, and then dividing the result by the pooled standard deviation [SD].

Cohen's $d=\left(M_{2}-M_{1}\right) / S D_{\text {pooled }}$

where:

$S D_{\text {pooled }}=\sqrt{ }\left(\left(S D_{1}^{2}+S D_{2}^{2}\right) / 2\right)$

- The calculation of the $\Delta$ of Glass (Glass's delta), using the formula proposed by its creator Gene Glass [11], in order to be able to calculate how different the groups to compare are. Glass's delta, which uses only the standard deviation of the control group, is an alternative measure if each group has a different standard deviation.

Glass's $\Delta=\left(M_{2}-M_{1}\right) / S D_{\text {control }}$

In an investigation carried out by Bisset, Paungmali, Vicenzino and Beller in 2005 [12] on the effectiveness of physical interventions in treatments of lateral epicondyle pain (tennis elbow), $\Delta$ is used and its magnitude is interpreted as follows: si $\Delta \leq 0.2$ low or weak; $\Delta$ between 0.3 and 0.7 moderate; and $\Delta \geq 0.8$ is considered high or strong [13].

In the case of the difference between two averages, generalized to any other statistical test, the strategies for interpreting the effect sizes are also a new option to evaluate and identify clinically relevant changes, independently of the unit of measurement considered and the size of the samples studied. In this sense, the calculation of effect sizes has been proposed, for example, as a system to assess 
whether certain detected changes in the health status of individuals, potentially induced by an intervention (e.g., a clinical trial), can be considered clinically relevant [14].

\section{Results:}

In the comparison of the total results of the Roland Morris Questionnaire obtained between the Group of the School of the Back and the Group of Pilates between the pre-treatment and the post-treatment of three months, an improvement has been obtained in the Group of the School of the Back of 1.66 points (6.96\%) and in the Pilates Group of 2.08 points $(8.69 \%)$, which indicates that the treatment given to the Pilates Group achieves an improvement of 0.41 points $(1.73 \%)$ higher than the Back School Group (Table 2). The results of the "Student's t-Test" test in both treatments, made by comparing the scores obtained in the pre-treatment and post-treatment phases, indicates the acceptance of the alternative hypothesis that shows significant differences between the pre and post treatments given to patients (p-value in both treatments of 0.001). Regarding the effect size of each treatment, the results showed that the effect sizes of the treatments in both groups are considered moderate-large (Table 1). 
Table 1. Comparison of Roland Morris results between treatment of the School Group of the Back and the Pilates Group

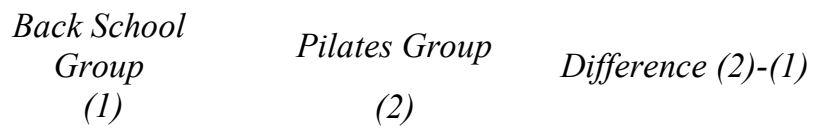

\begin{tabular}{|c|c|c|c|}
\hline $\begin{array}{l}\text { Pretreatment-posttreatment } \\
\text { (improvement obtained) }\end{array}$ & $1,66(6,96 \%)$ & $2,08(8,69 \%)$ & $0,41 \quad(1,73 \%)$ \\
\hline Cohen's d value & 0,92 & 1,01 & 0,09 \\
\hline Glass $\triangle$ value & 0,50 & 0,48 & $-0,02$ \\
\hline$p$-value & 0,001 & 0,001 & \\
\hline
\end{tabular}

Sig level $\mathrm{p}<0.05$

Cohen d-value clinical effect size: $>0.20$ and $<0.50$ small clinical effect size; $>0.50$ and $<0.80$ moderate clinical effect size and $>0.80$ high clinical effect size 24

Clinical effect size $\Delta$ value of Glass: $\leq 0.2$ low or weak; $\Delta$ between 0.3 and 0.7 moderate; and $\Delta \geq 0.8$ is considered highly strong 25

In the comparison of the total results of the Visual Analog Scale of pain obtained between the Group of the School of the Back and the Group of Pilates between the pre-treatment and the post-treatment after three months, an improvement has been obtained in the Group of the Back School of 1.42 points $(14.20 \%)$ and in the Pilates Group of 1.82 points $(18.20 \%)$, which indicates that the treatment given to the Pilates Group achieves an improvement of 0, 40 points (4\%) higher than the Back School Group. The results of the "Student's t-Test" test in both treatments, made by comparing the scores obtained in the pre-treatment and post-treatment phases, indicates the acceptance of the alternative hypothesis that shows significant differences between the previous and after treatments given to patients ( $p$-value in both treatments of 0.001). Regarding the size of the effect of each treatment, the results shown indicate that the size of the treatment effect in both groups show moderate to high results (Table 2). 
Table 2. Comparison between the treatments of the Group of the School of the Back and Pilates of the Visual Analogue Scale of pain.

$\begin{array}{ccc}\text { Back School } & \text { Pilates Group } & \\ \text { Group } & \text { Difference (2)-(1) } \\ \text { (1) } & \text { (2) } & \end{array}$

\begin{tabular}{|c|c|c|c|}
\hline \multicolumn{4}{|l|}{ Mean difference (MD) } \\
\hline $\begin{array}{l}\text { Pretreatment-posttreatment } \\
\text { (improvement obtained) }\end{array}$ & $1,42(14,20 \%)$ & $1,82(18,20 \%)$ & $0,40(4 \%)$ \\
\hline Cohen's d value & 0,99 & 1,32 & 0,33 \\
\hline Glass $\triangle$ value & 1,15 & 0,99 & $-0,16$ \\
\hline $\begin{array}{l}p \text {-value } \\
\text { Student's test }\end{array}$ & 0,001 & 0,001 & \\
\hline
\end{tabular}

Sig level $\mathrm{p}<0.05$

Cohen d-value clinical effect size: $>0.20$ and $<0.50$ small clinical effect size; $>0.50$ and $<0.80$ moderate clinical effect size and $>0.80$ high clinical effect size 24

Clinical effect size $\Delta$ value of Glass: $\leq 0.2$ low or weak; $\Delta$ between 0.3 and 0.7 moderate; and $\Delta \geq 0.8$ is considered highly strong 25

\section{Discussion:}

\section{$\underline{\text { Research limitations }}$}

1. In our study, it was only posible to perform the Pilates Method exercises using the basic-medium level because a complete 3 level Pilates program (basic, médium and high) required much more time tan what was available in this research. It mus be taken into account that the patients in our study started from a basic level to carry out the exercises, so a training Schedule was devoloped considering the ability to learn and adpat to their physical condition, in toder that the exercises wer carried out safely and effectively, controlling the performance of the exercises and avoiding excesses and level progressions that could have led to risks and injuries in our patients

2. It has not been possible to extend a greater number of weekly sessions or increase the sample due to exceeding the capacity of the Hospital facilities and the use of its Human Resources to be able to impart the treatments more than twice a week to each patient. This lack of capacity is due to the following circumstances that have been considered

A. An excessive number of patients under the supervision and control of the physiotherapist responsible for giving the treatments, can lead to inadequate practice due to poor supervision of the exercises which may cause different injuries to the patients and a significant decrease in the efficacy of the results. To avoid these risks, treatments have been given in small groups of a 
maximum of 5-8 patients, both from the School of the Back treatment and from the Pilates Method.

B. Apart of giving the treatments, object of this research, the rehabilitation of other patients with other pathologies other than chronic non-specific low back pain have continue, without compromising the quality and safety of these services and without affecting the usual care that these patients are given at the Hospital del Henares.

3.- Due to the nature of the treatments applied, both from the School of the Back and the Pilates Method, it has not been possible to perform the concealment of the physiotherapists of the Physiotherapy Unit of the Hospital del Henares. As this type of limitation is related in this and other forms of treatment, it was arranged that the evaluations of the treatments (Questionnaires and Scales to be completed by the patients) were delivered and collected, once completed by the participants, by physiotherapists other than the one had who had given the treatment. This does not prevent the clinical trial from having the greatest guarantees and being of the best therapeutic quality, since in this research, the randomization of patients, the random sequence, the evaluation of the evolution of patients and the analysis of the data have been blind.

-Roland Morris questionnaire.

Comparison of the pretreatment and posttreatment results after three months of the GEE, indicates a significant improvement of $1.66 \pm 1.81$ points (Mean difference $[\mathrm{MD}]$ Pretreatment-posttreatment $=1,66 ; 95 \%$ confidence interval $[\mathrm{CI}]=0,90$ to 2,43 ; $\mathrm{p}=0,001$ ) (Figure 2). Different investigations have been found using treatments from the School of the Back that show improvements in taking follow-up measures for 3 or 4 months, such as those carried out by the Portuguese Society of Rheumatology, held by de Andrade et al. [15] where twice a day sessions were given; the one carried out by García et al. [16] in which sessions were held every day of the week and the one by Ribeiro et al. [17] where sessions were held 5 times a week. These higher results are possibly due to the performance of different schedules in which a greater number of sessions were performed. 


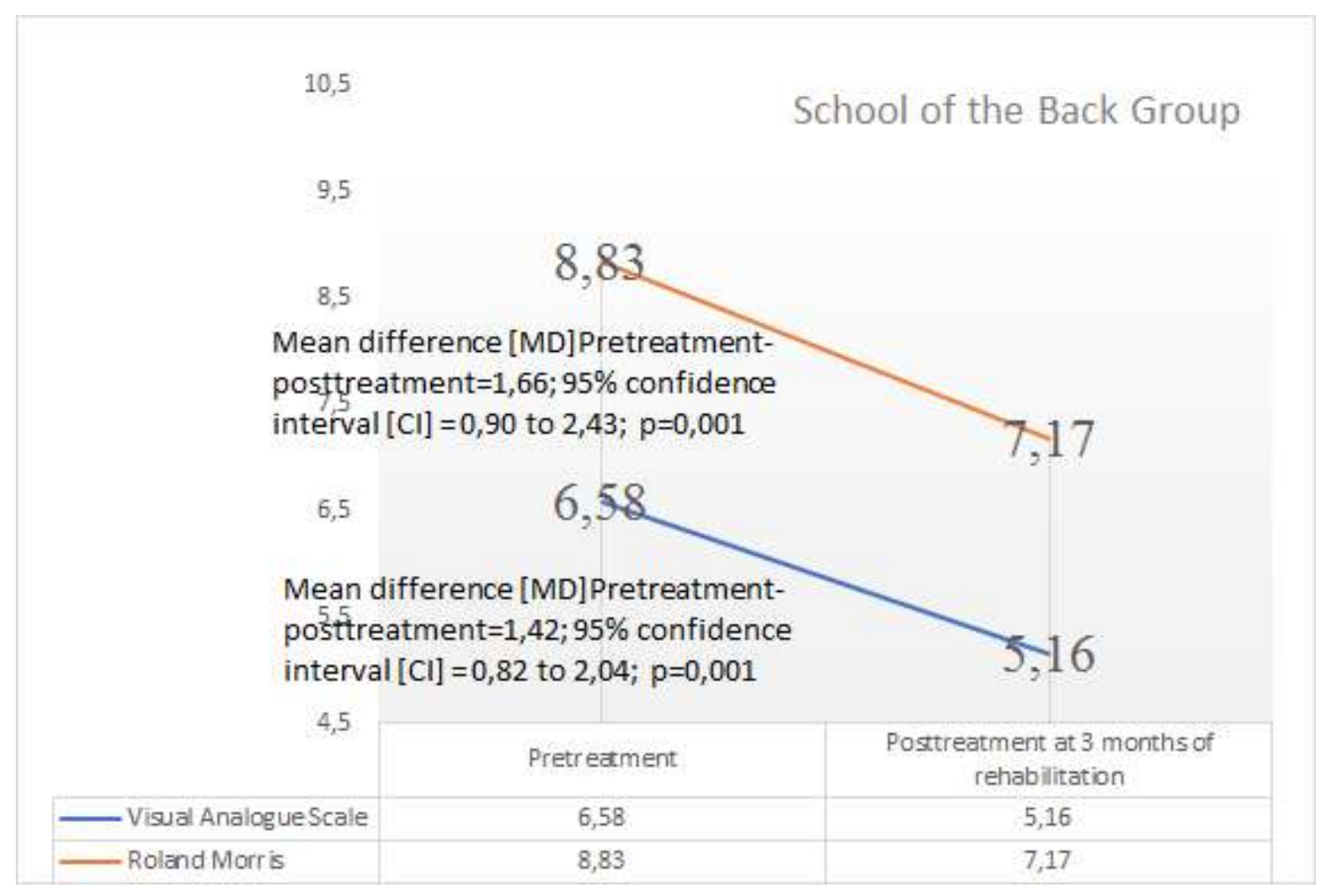

Figure 2. School of the Back Group's improvements obtained in physical disability and pain level at 3 months of rehabilitation.

Comparison of the pretreatment and posttreatment results after three months after GP, indicate a significant improvement of $2.08 \pm 2.06$ points (Mean difference [MD] Pretreatment-posttreatment $=2,08 ; 95 \%$ confidence interval $[\mathrm{CI}]=1,21$ to 2,$95 ; \mathrm{p}=0,001$ ) (Figure 3). Higher results have been obtained in investigations in which progressive programs in difficulty were carried out by performing Pilates exercises of the 3 basic, intermediate and advanced levels, such as the investigations carried out by da Luz et al.. [18]; Miyamoto et al. [19], superior results were also found in the one carried out by Natour et al. [20] which combined treatment with NSAIDs. Lower results are observed in the research by Quinn, et al. [21] and Notarnicola et al. [22], surely due to differences between the duration of the treatments carried out by us (1 weekly session for 8 weeks and 5 sessions a week for 25 weeks of treatment) respectively. 


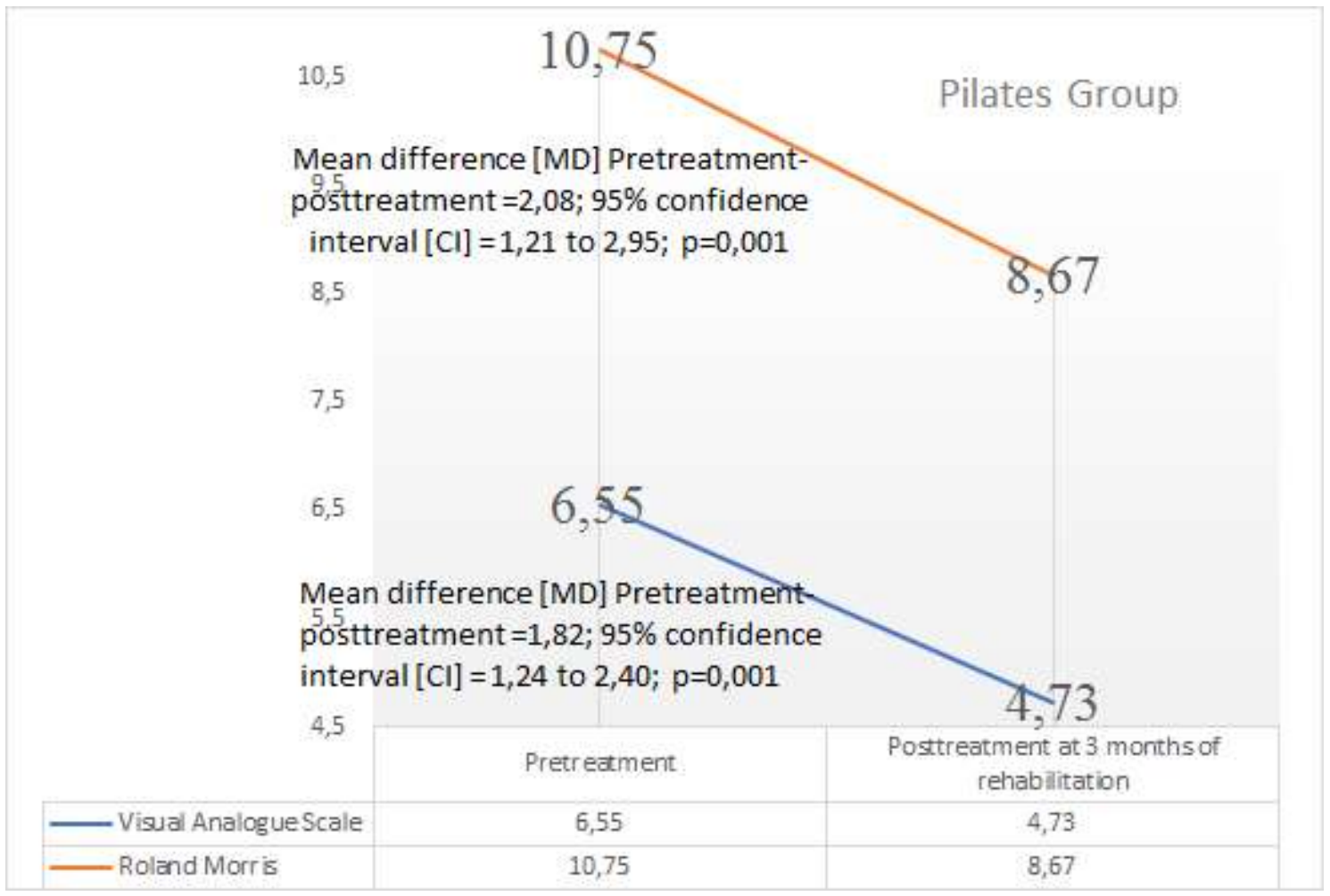

Figure 3. Pilates group improvements obtained in physical disability and pain level at 3 months of rehabilitation

Considering as a clinically relevant minimum change "the smallest difference in score within the tool with which we are measuring that is noted as beneficial for the patient and that would generate, without any side effect, and without excessive cost, changes approaching the problem of the patient [23], the improvement obtained by the GEE (1.66 points) is very close to the 2 points considered as a clinically relevant difference, taking into account the studies by Kovacs in 2005 [24] and Borbardier et al.. in 2016 [25]; and it is lower than the 3-4 points considered by Ostelo et al.. in 2004 [26] and Straford et al.. in 1996 [27]. Regarding the improvement obtained in the GP (2.08 points), it is considered clinically relevant in the studies by Kovacs [24] and Borbardier et al. [25] and is somewhat lower than the 3 points considered in the studies by Ostelo et al. [26] and Straford et al. [27] (Table3). 
Table 3. Clinically relevant difference of the results corresponding to the comparison of scores between pretreatment and posttreatment after three months of the Roland Morris Questionnaire, according to scientific studies on sensitivity of changes.

Scientific studies on sensitivity of changes indicating the minimum difference in score considered as clinically relevant.

\begin{tabular}{|c|c|c|c|c|c|c|}
\hline & & $\begin{array}{c}\text { score } \\
\text { difference } \\
\text { Pre-Post }\end{array}$ & $\begin{array}{l}\text { Kovacs et al.. } \\
2005 \\
\begin{array}{c}\text { Difference in } 2 \\
\text { points }\end{array}\end{array}$ & $\begin{array}{c}\text { Bombardier } \\
\text { et al.. } 2001 \\
\text { Difference in } \\
2 \text { points }\end{array}$ & $\begin{array}{l}\text { Ostelo et al.. } \\
\quad 2004 \\
\text { Difference in } \\
\text { 3-4 points }\end{array}$ & $\begin{array}{l}\text { Straford y et } \\
\text { al.. } 1996 \\
\text { Difference in } \\
\text { 3-4 points }\end{array}$ \\
\hline $\begin{array}{l}\text { Pilates } \\
\text { Group }\end{array}$ & Effect & 2,08 & YES & SI & NO & $\mathrm{NO}$ \\
\hline $\begin{array}{l}\text { School of } \\
\text { Back } \\
\text { Group }\end{array}$ & $\begin{array}{l}\text { clinically } \\
\text { relevant }\end{array}$ & 1,66 & $N O$ & NO & NO & NO \\
\hline
\end{tabular}

\section{Analog Visual Scale (AVS).}

The comparison of the improvement results (difference in means between pre-treatment and post-treatment after three months) between the GEE and the GP, indicates that the difference in the averages in the GEE is 1.42 points (Mean difference [MD]Pretreatmentposttreatment $=1,42 ; 95 \%$ confidence interval $[\mathrm{CI}]=0,82$ to 2,$04 ; \mathrm{p}=0,001$ ) (Figure 2 ) and in the GP of 1.82 points (Mean difference [MD] Pretreatment-posttreatment $=1,82 ; 95 \%$ confidence interval $[\mathrm{CI}]=1,24$ to 2,$40 ; \mathrm{p}=0,001$ ) (Figure 3 ), resulting in a superior improvement of the GP of 0.40 points (Table 2 ).

Our results coincide with those obtained in the study by Donzelli et al. [28] when verifying how both treatments reduce pain intensity measured using the Visual Analogical Scale, as well as that the results of the GP show reductions in pain intensity greater than the GEE.

In the study by Donzelli et al.., The result of improvement in the GP was 2.8 points and in the GEE 2.45 points, resulting in a higher improvement of the GP of 0.35 points. As well as in our methodology, they only used the basic level of exercises in the Pilates program because a complete 3-level Pilates program (basic, medium and high) would require much more time, the fundamental difference with our study being the number of sessions performed and weeks of sessions performed (12 weeks of treatment with 2 sessions a week versus 10 consecutive treatment sessions in the research by Donzelli et al. [28].

Regarding the clinically relevant minimum change, the improvement obtained by the GEE (1.43 points) is considered clinically relevant in the studies by Todd et al. [29] and Gallagher et al. [30] and is somewhat less than 1,5-2 points considered as clinically relevant difference in the studies by Ostelo et al. [31] and Kovacs [32]. The superior improvement obtained in the GP (1.82 points) is considered clinically relevant in the studies by Todd et al. [29]; Gallagher et al..[30] and Kovacs [32] and is very close to the 
2 points considered in the study by Ostelo et al. [31] (Table 4). The above results on clinically relevant minimal change coincide with the consideration of the sizes of the effects of the treatments as a large effect in both groups (Table 5).

Table 4. Clinically relevant difference of the results corresponding to the comparison of scores between pre-treatment and post-treatment after three months of the Visual Analog Pain Scale, according to scientific studies on sensitivity of change.

\begin{tabular}{|c|c|c|c|c|c|c|}
\hline & & \multirow{3}{*}{$\begin{array}{l}\text { score } \\
\text { difference } \\
\text { Pre-Post. }\end{array}$} & \multicolumn{4}{|c|}{$\begin{array}{l}\text { Scientific studies on sensitivity of changes indicating } \\
\text { the minimum score difference considered as clinically } \\
\text { relevant. }\end{array}$} \\
\hline & & & $\begin{array}{l}\text { Todd et al.. } \\
\quad 1996\end{array}$ & $\begin{array}{l}\text { Gallagher } \\
\text { et al.. } 2001\end{array}$ & $\begin{array}{l}\text { Ostelo et al.. } \\
\quad 2005\end{array}$ & $\begin{array}{c}\text { Kovacs. } \\
2016\end{array}$ \\
\hline & & & $\begin{array}{l}\text { Diferencia } \\
\text { en } 1,3 \\
\text { puntos }\end{array}$ & $\begin{array}{l}\text { Diferencia } \\
\text { en } 1,3 \\
\text { puntos }\end{array}$ & $\begin{array}{l}\text { Diferencia } \\
\text { entre } 2 \\
\text { puntos }\end{array}$ & $\begin{array}{l}\text { Diferencia } \\
\quad \text { en } 1,5 \\
\text { puntos }\end{array}$ \\
\hline $\begin{array}{l}\text { School of Back } \\
\text { Group }\end{array}$ & $\begin{array}{l}\text { Effect } \\
\text { clinicallv }\end{array}$ & 1,43 & $S I$ & SI & NO & NO \\
\hline Pilates Group & relevant & 1,82 & $S I$ & SI & NO & SI \\
\hline
\end{tabular}

Table 5. Differences of means and size of the treatment effect of the total results of the Visual Analogue Pain Scale (calculation of Cohen's d and Glass's between pretreatment and post treatment after three months).

$\begin{array}{cccccc}\text { Mean } & \text { Pooled } & & & \text { Size of the } \\ \text { difference } & \text { standard } & \text { pretreatment } & \text { Cohen's } & \Delta \text { value } & \text { Seviation } \\ \text { standard } & \text { d-value } & \text { of Glass } & \text { treatment (effect } \\ \text { deviation } & & & & \text { size) }\end{array}$

$\begin{array}{llllllll}\begin{array}{l}\text { School of Back } \\ \text { Group }\end{array} & 24 & 1,43 & 1,44 & 1,23 & 0,99 & 1,15 & \text { High effect }\end{array}$

$\begin{array}{lllllll}\text { Pilates Group } & 24 & 1,82 & 1,37 & 1,84 & 1,32 & 0,99\end{array}$ High effect

Cohen's d-value clinical effect size: $>0.20$ and $<0.50$ small clinical effect size; $>0.50$ and $<0.80$ moderate clinical effect size and $>0.80$ high clinical effect size2 4

Clinical effect size $\Delta$ value of Glass: $\leq 0.2$ low or weak; $\Delta$ between 0.3 and 0.7 moderate; and $\Delta \geq 0.8$ is considered high or strong 25

\section{Conclusions. -}

The results obtained in this research indicate that the Pilates Method can be considered as an alternative non-specific low back pain treatment to the School of the Back, by providing higher improvements both in terms of functional disability and pain intensity. 


\section{Ethical aspects}

The clinical trial will be carried out according to the ethical principles originated in the

Helsinki's Declaration and the current legislation

->Helsinki's Declaration of the World Medical Association: Ethical Principles for Medical Research in Humans. Adopted by the 18th World Medical Assembly, Helsinki, Finland, June 1964 and amended in subsequent reviews (Tokyo, 1975; Venice, 1983; Hong Kong, 1989; Somerset West, 1996; Edinburgh, 2000; clarification note Washington, 2002; clarification note Tokyo, 2004; Seoul, 2008; and Fortaleza, 2013)

-> Law 41/2002, on Patient Autonomy

-> Organic Law 15/1999, of December 13, on the Protection of Personal Data. BOE no. 298 of December 14, 1999

Informed consent was obtained and freely granted by each patient prior to their participation in the clinical trial. Prior to signing the consent, the Information sheet was delivered for their knowledge:

The research study was submitted for evaluation and compliance to the Occupational Therapy and Physiotherapy Unit of the Hospital del Henares and the Research Ethics Committee of the Hospital de la Princesa (Committee to which the Hospital del Henares belongs), receiving the approval to be held on November 23, 2015.

\section{Consent for publication}

Not applicable

\section{Availability of data and materials}

Not applicable

\section{Competing interests}

The authors declare that they have no competing interests.

\section{Funding}

Not applicable

\section{Authors' contributions}

LMMM is the Chief Investigator; he conceived the study, led the proposal and protocol development,

CFJJ contributed to study design and to development of the proposal (Logistics)

RFEM contributed to study design and to development of the proposal

LRA was the lead trial methodologist 


\section{Acknowledgements}

Not applicable

\section{References}

1. García, A. O., Mendiola, A. H., Peña, J. I., Carmona, L., EPISER Study Group. Population impact of low back pain in Spain: results of the EPISER study. Rev Esp. Reumatol 2002; 29 (10): 471-8.

2. Bumbiedro, S. A., Pérez, F. G. Importance of physical exercise in the treatment of non-specific low back pain. Rehabilitation: (Madrid) 2003; 37 (6): $323-32$.

3. Humbría A, Carmona L, Ortiz AM, Peña JL. Treatment of non-specific low back pain: what does the medical literature tell us? Rev Esp. Reumatol. 2002; 29: 494-8.

4. Casado Morales M. a Isabel, Moix Queraltó Jenny, Vidal Fernández Julia. Etiology, persistence and treatment of low back pain. Clinic and Health [Internet]. 2008 Dec [cited 2020 Apr 18]; 19 (3): 379-392

5. Pita Fernández S., López de Ullibarri Galparsoro I., Necessary number of patients to treat to reduce an event. Cad Aten Primaria, Coruña Spain, 1998, 96-98

6. SERMEF: Web Site of the Spanish Society for Rehabilitation and Medicine. [web site]. Madrid: SERMEF [access 10 January 2016]. Available at: http://www.sermef-ejercicios.org

7. Isacowitz R, Clippinger K. Anatomy of Pilates. 2nd ed. Madrid: Tutor; 2011.

8. Cohen J. Statistical Power Analysis for the Behavioral Sciences. 2nd. ed. New York: Lawrence Erlbaum Associates; 1988

9. Anderson, G. The Role of Meta-Analysis in the Significance Test Controversy. European Psychologist, 1999; 4 (2): 75-82.

10. Hunter, J.E. y Schmidt, F.L. Methods of Meta-Analysis. Correcting Error and Bias in Research Findings. Second Edition. Thousand Oaks, CA: Sage, 2004

11. Glass, G.V.; McGaw, B. y Smith, M.L. Meta-analysis in Social Research. Beverly Hills, CA: SAGE. 1981

12. Bisset L, Paungmali A, Vicenzino B, Beller E. A systematic review and metaanalysis of clinical trials of physical interventions for lateral epicondylalgia. Br J Sports Med. 2005; 39 (7): 411-22

13. Thomas JR, Nelson JK, Silverman SJ. Research Methods in Physical Activity: $1^{a}$ ed. Champaign, IL: Human Kinetics; 2005

14. Casado A, Prieto L, Alonso J. The effect size of the difference between two means: statistically significant or clinically relevant? Med Clin. 1999; 112: 15 
15. Andrade SC, Araújo AGR, Vilar MJ. Coluna School for patients with nonspecific chronic pain: Benefits of the Association of Exercises and Patient Education. Official organization of the Portuguese Society of Rheumatology. 2008; 33: 443-50.

16. Garcia AN, Costa Lda C, da Silva TM, Gondo FL, Cyrillo FN, Costa RA, et al.. Effectiveness of back school versus McKenzie exercises in patients with chronic nonspecific low back pain: a randomized controlled trial. Phys Ther. 2013; 93: 729-47. [PMID: 23431213] doi: 10.2522 / ptj.20120414

17. Ribeiro LHC, Simões MFJ, Jones A, Natour J. Effectiveness of a school program in low back pain. Clin. Experim Rheumatol. 2008; 26: 81-8.

18. da Luz, M.A., Costa, L.O., Fuhro, F.F., Manzoni, A.C., Oliveira, N.T. y Cabral, C.M. Effectiveness of mat Pilates or equipment-based Pilates exercises in patients with chronic nonspecific low back pain: a randomized controlled trial. Phys Ther. 2014; 94 (5): 623-31.

19. Miyamoto G, Oliveira L, Galvanin T, Nunes C. Efficacy of the addition of modified Pilates exercises to a minimal intervention in patients with chronic low back pain: a randomized controlled trial. Phys Ther. 2013; 93 (3): 310-20. [PMID: 23064732] doi: 10.2522 / ptj .20120190

20. Natour J, Cazotti LdeA., Ribeiro LH, Baptista AS, Jones A. Pilates improves pain, function and quality of life in patients with chronic low back pain: a randomized controlled trial. Clin Rehabil. 2015; 29(1): 59-68.

21. Quinn K, Barry S, Barry L. Do patients with chronic low back pain benefit from attending Pilates classes after completing conventional physiotherapy treatment? Physiotherapy Ireland. 2011; 32(1): 5-12.

22. Notarnicola A, Fischetti F, Maccagnano G, Comes R, Tafuri S, Moretti B. Daily pilates exercise or inactivity for patients with low back pain: a clinical prospective observational study. Eur J Phys Rehabil Med. 2014; 50(1): 59-66.

23. Jaeschke R, Singer J, Guyatt GH. Measurement of health status. Ascertaining the minimal clinically important difference. Control Clin Trials. 1989;10(4): 407-415.

24. Kovacs FM. El uso del cuestionario de Roland-Morris en los pacientes con lumbalgia asistidos en Atención Primaria. Red Española de Investigadores en Dolencias de la Espalda. SEMERGEN. 2005; 31(7): 331-5.

25. Bombardier C, Hayden J, Beaton DE. Minimal clinically important difference in low back pain outcome measures. J Rheumatol. 2001; 28(2):431-8.

26. Ostelo RW, de Vet HC, Knol DL, Van den Brandt PA. 24-ítem Roland- Morris Disability Questionnaire was preferred of six functional status questionnaires for post-lumbar disc surgery. J Clin Epidemiol. 2004; 57(3): 268-76.

27. Stratford P, Binkley J, Solomon P, Finch E, Gill C, Moreland J. Defining the Minimum Level of Detectable Change for the Roland and Morris Questionnaire. Phys Ther. 1996; 76(4): 359-65. 
28. Donzelli S, Di Domenica E, Cova AM, Galletti R, Giunta N. Two different techniques in the rehabilitation treatment of low back pain: a randomized controlled trial. Eura Medicophys. 2006; 42(3): 205-10.

29. Todd KH, Funk KG, Funk JP, Bonacci R. Clinical significance of reported changes in pain severity. Ann Emerg Med. 1996; 27(4):485-9.

30. Gallagher EJ, Liebman M, Bijur PE. Prospective validation of clinically important changes in pain severity measured on a visual analog scale. Ann Emerg Med. 2001; 38(6): 633-8.

31. Ostelo RW, de Vet HC. (2005). Clinically important outcomes in low back pain. Best Pract Res Clin Rheumatol. 2005; 19(4): 593-607.

32. Kovacs.org. Minimal magnitude of changes in pain intensity and degree of disability that are relevant to patients with low back pain. [articles on the internet]. 2016 [accessed January 8, 2017]. Available at: http://www.kovacs.org/es_quehacemos_investigacionmedica_actividadyresu ltados_proyectosdeinvestigacionyaconcluidossobredolenciasdelcuelloylaespa 1da_06.html 


\section{Figures}

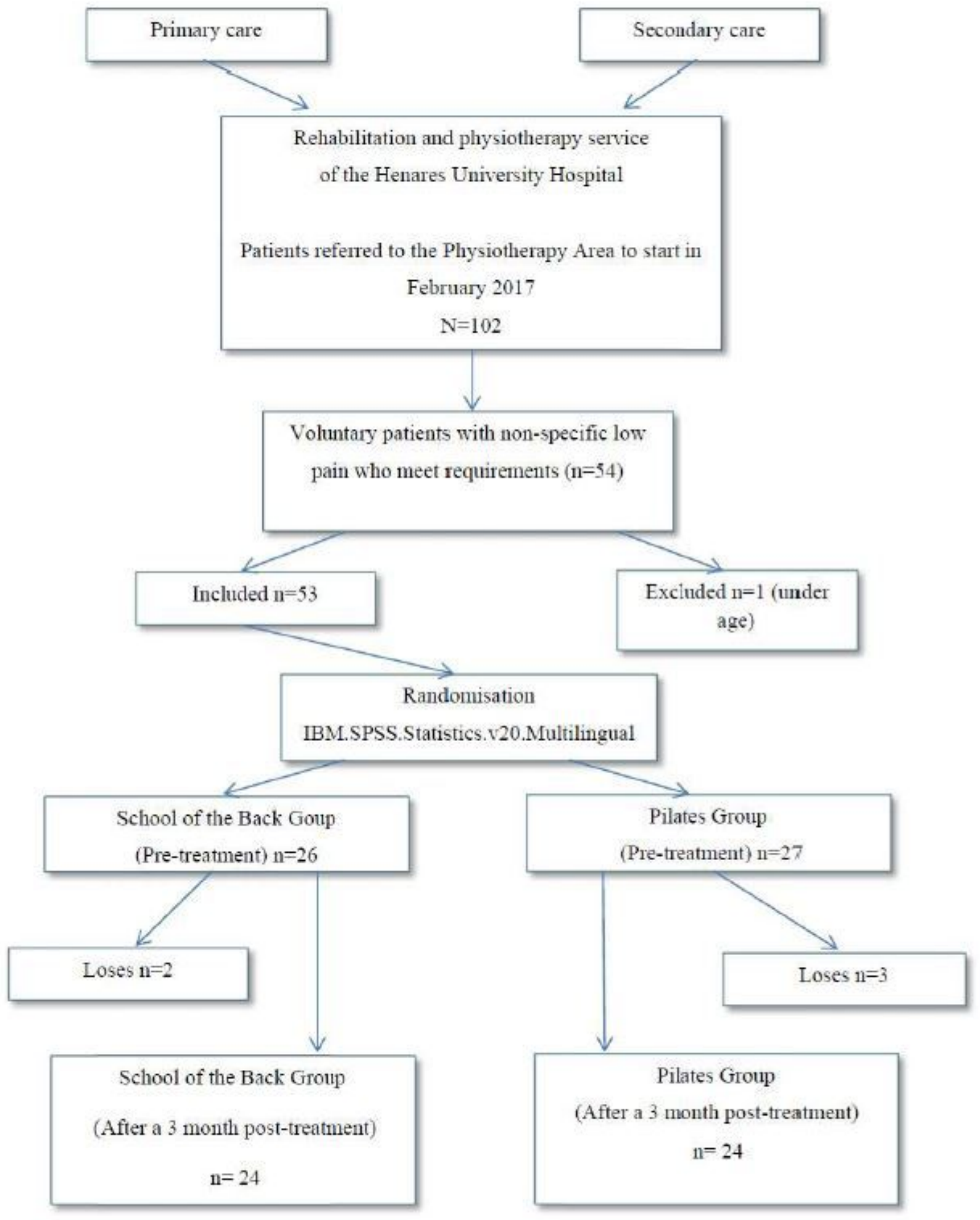

\section{Figure 1}

Study Design. Recruitment, randomization to treatment, and voluntary recruitment of participants. 
10,5

\section{School of the Back Group}

\section{9,5}

8,5

8,83

Mean difference [MD]Pretreatmentposttreatment $=1,66 ; 95 \%$ confidence interval $[\mathrm{Cl}]=0,90$ to 2,$43 ; p=0,001$

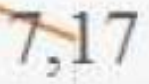

6,5

6,58

Mean difference [MD] Pretreatmentposttreatment $=1,42 ; 95 \%$ confidence interval $[\mathrm{Cl}]=0,82$ to 2,$04 ; \mathrm{p}=0,001$

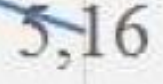

4,5

\begin{tabular}{ll|l|l|l|}
4,5 & Pretreatment \\
\hline
\end{tabular}

Postreatment at 3 months of rehabilitation

6,58

5,16

8,83

7,17

Figure 2

School of the Back Group's improvements obtained in physical disability and pain level at 3 months of rehabilitation. 


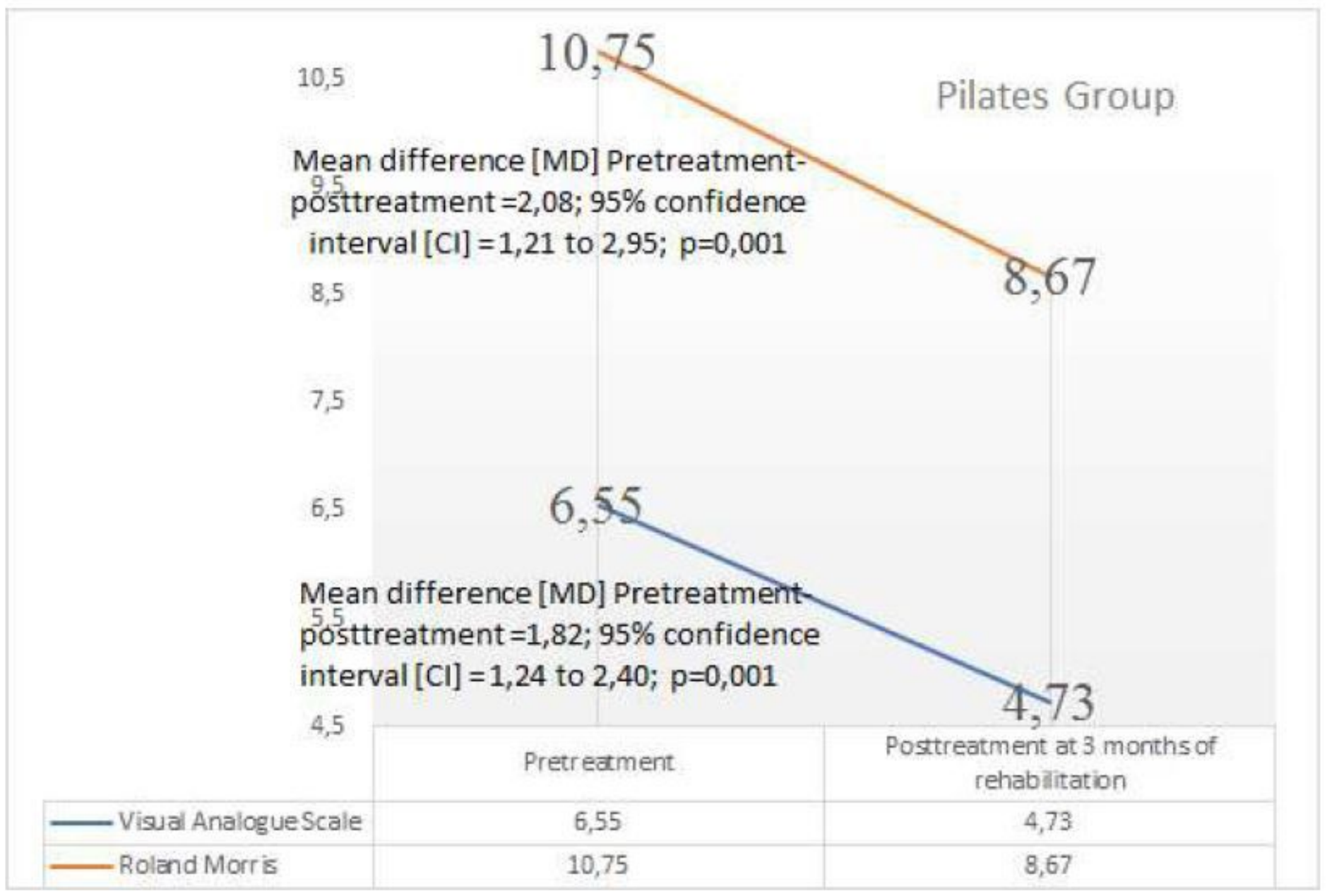

Figure 3

Pilates group improvements obtained in physical disability and pain level at 3 months of rehabilitation

\section{Supplementary Files}

This is a list of supplementary files associated with this preprint. Click to download.

- CONSORT2010ChecklistMSWord.doc 